\title{
ACUTE DONATH-LANDSTEINER HEMOLYTIC ANAEMIA (DL-HA) IN A 5-YEAR OLD MALE CHILD - HOW TO TREAT?
}

\author{
Gautam Araya. \\ Department of Pediatrics, Bicol Christian College of Medicine, Ago General Hospital, Lalitpur, Nepal.
}

\section{Keywords}

DL-HA, antibody, bilirubin, fever, assay

\author{
ARTICLE HISTORY \\ Received 18 February 2021 \\ Accepted 16 March 2021
}

\section{Clinical Problem:}

A 5-year-old male present to the emergency department with fever for 8 days and acute onset of dark coloured urine. There was no bleeding from any other site. Five days ago, he was prescribed amoxicillin-clavulanate for infection of the ear and suspected tonsillitis. On examination, his temperature was $103.6^{\circ} \mathrm{F}$, heart rate was $90 / \mathrm{min}$, respiratory rate was $18 / \mathrm{min}$, oxygen saturation was $98 \%$ at room air. He had jaundice and pallor. Systemic examination was normal. Investigations showed initial hemoglobin $10.4 \mathrm{~g} / \mathrm{dL}$ which decreased to $5.8 \mathrm{~g} / \mathrm{dL}$ after 37 hours. Haptoglobin was $12 \mathrm{mg} / \mathrm{dl}$ and serum indirect bilirubin was $1.8 \mathrm{mg} / \mathrm{dl}$. Peripheral blood smear showed erythrophagocytosis (Figure 1). He was suspected to have acute Donath-Landsteiner hemolytic anaemia (DL-HA). A prompt Donath-Landsteiner (DL) test was performed, which confirmed the presence of a DL antibody and thus our diagnosis.

Figure 1. Peripheral blood smear test showing erythrophagocytosis

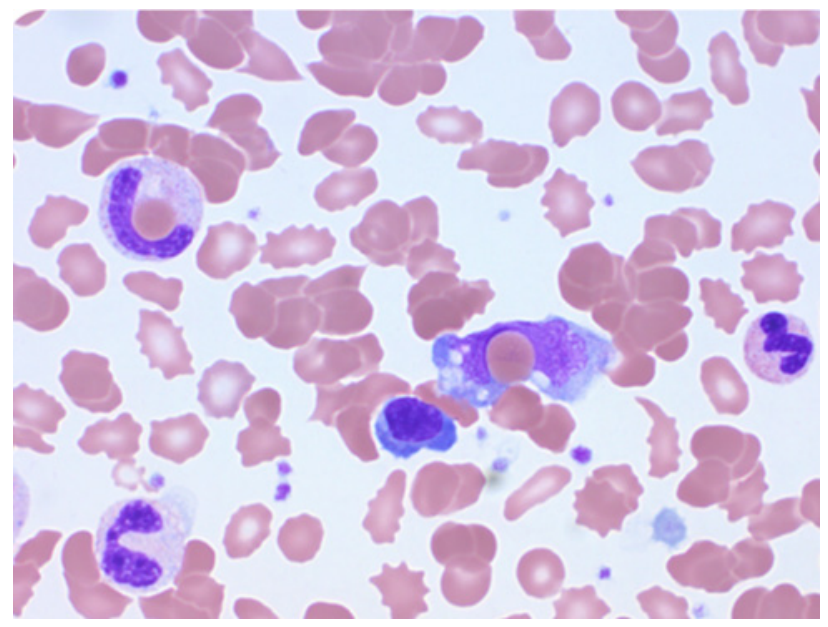

How to treat this patient?

Address for Correspondance: Gautam Araya, Department of Pediatrics, Bicol Christian College of Medicine, Ago General Hospital, Rizal Street, Legaspi City, Lalitpur, Nepal.

Email: araya.cu@gmail.com

(C2021 Pediatric Oncall

\section{Discussion:}

DL-HA represents $30-40 \%$ of autoimmune hemolytic anemia in children, that is generally selflimiting. ${ }^{1}$ Autoantibody responsible for DL-HA is a coldreacting immunoglobulin known as, DL autoantibody, capable of causing severe hemolysis even when the titre detected is low. ${ }^{2}$ The DL autoantibody hold on tightly to red blood cell (RBC) surfaces during the peripheral circulation, where temperatures are cooler than $30^{\circ} \mathrm{C}$ in comparison to core body temperature. ${ }^{3}$ After attachment to RBC surface, the DL autoantibody activates the complement cascade, leading to RBC membrane perforation and intravascular hemolysis, hence the dark coloured urine. ${ }^{3}$ Complement activation and consequential hemolysis would become reality if binding RBCs travel to the core part of the body at a warmer temperature. Results of the direct antiglobulin test (DAT) with anti-C3 are likely to be positive, while negative for anti-IgG or anti-IgM. ${ }^{3}$ In contrast, in cold agglutinin disease (CAD) IgM is positive. ${ }^{3}$ The most prominent difference between DL-HA and CAD is this causative agent. Hence, a distinction must be established for proper diagnosis and treatment. Given that hemoglobinuria and personal history of travel to cold areas is not always present, diagnosis relies on lab testing. ${ }^{2}$ A peripheral smear is always essential for diagnosis of hemolytic anaemia and may reveal spherocytes, or rouleaux formation suggestive of warm autoimmune haemolysis. ${ }^{4}$ The best initial therapy for this patient is to keep him warm with gloves and warming blanket. ${ }^{4}$ Warm intravenous fluids and red blood cell transfusion are vital for treatment. ${ }^{4}$ If an underlying etiology is determined, it should be treated. The most likely etiology for this patient's DL-HA is the history of a previous viral illness and initiation of amoxicillin-clavulanate (drug-induced immune hemolytic anaemia). Though corticosteroids represent the first-line treatment for patients with autoimmune hemolytic anaemia, about $30 \%$ of patients require second-line treatment. ${ }^{5}$ Plasmapheresis should only be used in severe cases, that are refractory to initial therapy. ${ }^{4}$

\section{Compliance with ethical standards \\ Funding: None \\ Conflict of Interest: None}

\section{References:}

1. Eder AF. Review: acute Donath-Landsteiner hemolytic 
anemia. Immunohematology. 2005;21:56-62. Erratum in: Immunohematol. 2005;21:132.

2. Emedicine. Donath-Landsteiner Hemolytic Anemia. Available at URL: https://emedicine.medscape.com/ article/955176-overview. Accessed on 28th Feb 2021.

3. Ogose T, Wakata Y, Kaneko M, Shinahara K, Takechi $T$, Kotani H. A case of recurrent paroxysmal cold hemoglobinuria with the different temperature thresholds of Donath-Landsteiner antibodies. J Pediatr Hematol Oncol.
2007;29):716-719.

4. American Society of Hematology. Case Study: Four-YearOld Male with Red Urine and Fever. Available from URL: https://www.hematology.org/education/trainees/fellows/ case-studies/child-red-urine-fever. Accessed on 5th March 2021.

5. Lechner $\mathrm{K}$, Jäger $\mathrm{U}$. How I treat autoimmune hemolytic anemias in adults. Blood. 2010;116:1831-1838. 